\title{
Trophobiosis in the arboricolous ant Liometopum microcephalum (Hymenoptera: Formicidae: Dolichoderinae)
}

\author{
JiŘi SCHLAGHAMERSKÝ' ${ }^{1}$ JAN KAŠPAR $^{1}$, LENKA PETRÁKOVÁ ${ }^{1}$ and VLADIMÍR ŠUSTR ${ }^{2}$ \\ ${ }^{1}$ Masaryk University, Faculty of Science, Department of Botany and Zoology, Kotlářská 2, 61137 Brno, Czech Republic; \\ e-mail: jiris@sci.muni.cz \\ ${ }^{2}$ Biology Centre of the ASCR, Institute of Soil Biology, Na Sádkách 7, 37005 České Budějovice, Czech Republic; \\ e-mail: sustr@upb.cas.cz
}

Key words. Hymenoptera, Formicidae, Dolichoderinae, Liometopum, arboricolous, ants, trophobiosis, foraging, honeydew

\begin{abstract}
The arboricolous dolichoderine ant Liometopum microcephalum (Panzer, 1798) is considered to be mainly predatory, although there are some reports of it tending aphids. The main objective of the present study was to confirm that this ant has a trophobiotic relationship with aphids and assess seasonal differences in its utilization of honeydew. We hypothesized that the worker ants on trees where they have their nest (nest tree) and trees where they are foraging (foraging trees) should differ in gaster mass and sugar content depending on their direction of movement, and that both should be highest in spring. From spring to summer 2009, ascending and descending workers were collected from nest and foraging trees at a locality in South Moravia, Czech Republic. Mass of their gasters and their content of total and reducing sugars were measured using chemical (photometric) methods. Differences in gaster mass confirmed the flow of liquid food from foraging to nest trees, but there were no significant between-month differences. Contents of total and reducing sugars were positively correlated with gaster mass. The gasters of workers descending from foraging trees contained significantly more reducing sugars than those of workers descending or ascending nest trees. The content of reducing sugars was lowest at the beginning of the ants' activity period in April and highest in June, with a non-significant drop in July. Results for total sugars were similar, with the decrease in July being significant. The concentration of sugars in the gasters of workers ascending and descending nest trees did not differ significantly but the absolute content of total sugars was higher in the gasters of ascending ants. Results from foraging trees confirmed that the ants collected the honeydew from these trees. Possible reasons for the ambigous results for nest trees are discussed. We conclude that trophobiosis is an important component of the nutritional biology of L. microcephalum.
\end{abstract}

\section{INTRODUCTION}

Trophobiosis, the mutualistic relationship between ants and insects (trophobionts, mainly some groups of Hemiptera and Lepidoptera), which produce sugar-rich exudates that in most cases are termed honeydew, is important in the nutritional biology of many species of ants (Hölldobler \& Wilson, 1990). The nutrient flow in terrestrial ecosystems can be substantially shaped by such relationships, if ants with their trophobionts are a dominant element of the ecosystem: wood ants (Formica rufa group) in boreal forests, for instance, transport large quantities of carbon, nitrogen and phosphorus into their nests, of which at least $54 \%, 70 \%$ and $57 \%$, respectively, are collected in the form of honeydew.

The dolichoderine ant Liometopum microcephalum (Panzer, 1798) is the only species of this genus living in Europe (Seifert, 2007). It is arboricolous, thermophilous and lives in the north of its range predominantly on floodplains (forests and open landscape) where it builds its nests several metres above ground in the trunks of old but mostly still healthy trees, mainly oaks (Schlaghamerský \& Omelková, 2007). From the nest trees conspicuous trails lead to other trees in the vicinity and up into their crowns ("foraging trees"). Colonies can be very large, consisting of probably hundreds of thousands of individuals, which guard territories that include many nest trees:
Wiest (1967) reports a territory size of up to $600 \mathrm{~m}^{2}$ and Makarevich (2003) a colony with several interconnected permanent and temporary nests and visiting 23 foraging trees. Due to the large size of Liometopum colonies, their feeding behaviour has to affect substantially the nutrient flow and biotic community in their vicinity. Although Mayr (1885) assumed that the only reason for L. microcephalum to visit trees other than the one in which it nests could be aphid tending, the species was considered to be mainly a predatory ant, living almost exclusively on animal food, by renowned myrmecologists: According to Forel (1892) "plant-lice [aphids] (are) heartily despised by the Liometopum" (translation by Wheeler, 1905); Emery (1891) held the same opinion based on his own observations. As already pointed out by Wheeler (1905), this would be a substantial difference to North American species, which have trophobiotic relationships with aphids and coccids. Velasco Corona et al. (2007) report that Liometopum appiculatum in Tlaxcala, Mexico, has a trophobiotic relationship with 14 species of Sternorrhyncha. The particularly high $\Delta{ }^{15} \mathrm{~N}$ reported in L. microcephalum (albeit based on a sample from a single colony) compared to other ant species would indeed indicate a predominance of zoophagy in this species (Fiedler et al., 2007). However, contrary to the preceding claims of strict zoophagy in L. microcephalum, Wiest (1967) reports 
from a site in Austria that the trails of L. microcephalum also lead to bark aphids of the genus Stomaphis. She observed L. microcephalum workers tending these aphids and transporting them to their nest in November, presumably for overwintering in the ant nest. Makarevich (2003) reports the tending of Stomaphis longirostris by a small population of L. microcephalum in the region of the Dnieper river (Ukraine). These two papers are the only published primary sources of trophobiosis occurring in $L$. microcephalum. However, they report only observational data with little detail and no quantification. In South Moravia, we have also observed L. microcephalum tending Stomaphis quercus (unpubl. observ.). Thus we reject the claim that Stomaphis quercus has an obligate relationship with Lasius fuliginosus (e.g. Goidanich, 1959; Hopkins \& Thacker, 1999; Stadler \& Dixon, 2008). We found also other aphids potentially utilized by $L$. microcephalum on its nest and foraging trees, in particular Lachnus roboris (unpubl. observ.).

In the canopies of tropical forests, where many more species of ants are truly arboricolous, tree-dwelling trophobionts are monopolized by the most common species of ants in the canopy, with dominant colonies and species of ants maintaining mutually exclusive territories (Blüthgen et al., 2000). Of all the European ants that are high in the behavioural hierarchy of ant assemblages, $L$. microcephalum is probably the most arboricolous (and much more so than for instance its North American cogeners that frequently nest on the ground); it competes for foraging trees with other dominant ants, such as Lasius fuliginosus and Formica rufa (Petráková \& Schlaghamerský, 2011). It is very questionable, if the large colonies formed by L. microcephalum could be supported by predation alone; thus a more direct link to primary production, via tree sap processed by aphids, seems probable, which would have implications for energy flow in ecosystems where L. microcephalum occurs.

The objectives of the present study were to confirm that trophobiosis occurs in L. microcephalum and assess its importance for this species. In particular, we wanted to confirm that foraging trees are visited (also) to collect honeydew and assess whether there are seasonal differences in the use of trophobiosis. Envisaging a situation in which workers with empty gasters leave nests to collect honeydew on foraging trees and then return to the nest trees with full gasters (Fig. 1), we formulated the following hypotheses: (1) gasters of workers descending from a nest tree should contain less sugars, in particular reducing sugars, than those of workers ascending these trees; (2) gasters of workers ascending a foraging tree should contain less (reducing) sugars than those of workers descending from these trees; (3) sugar content of Liometopum gasters should be highest in spring, when the colony needs "fast energy"; (4) honeydew is the major liquid transported in the crop (located within the gaster) and thus gaster mass will change with sugar content.

Liquid food collected by ant workers is stored in the crop situated in the gaster and is used by the individual ants as well as for the feeding of other adults and larvae

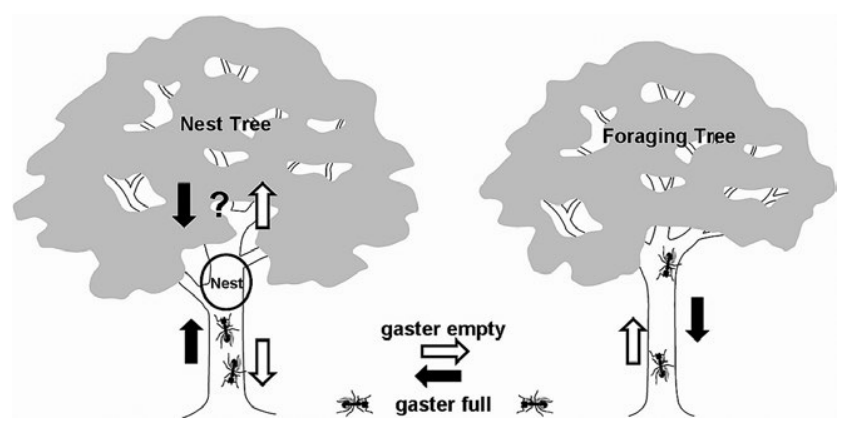

Fig. 1. Directions of movement of Liometopum microcephalum and transport of honeydew between nest and foraging trees. Movement between nest and crown of the nest tree is assumed (therefore the question mark) as it was not studied.

in the colony. Honeydew contains not only various kinds of sugars that can be utilized by ants and is a valuable short-term energy source, but may also contain amino acids, proteins and lipids suitable for ant nutrition (Boevé \& Wäckers, 2003; Blüthgen et al., 2004). Nevertheless, sugars are the main component of honeydew (90-95\% by dry weight, Hölldobler \& Wilson, 1990) and in the absence of any other potential source (floral or extrafloral nectaries), large quantities in ant gasters could indicate that the ants, either collect it directly by "milking" the trophobionts, or from the surface of leaves where it falls after being excreted. Non-reducing sugars such as melezitose, saccharose and trehalose may comprise up to $90 \%$ of total honeydew sugars but often substantially less (Fischer et al., 2005). Trehalose is also synthesized and is an important "blood-sugar" of insects, as it is major form of energy storage (Hölldobler \& Wilson, 1990; Schilman $\&$ Roces, 2008). As there is a high concentration of nonreducing trehalose in the haemolymph of well-fed ant workers (Schilman \& Roces, 2008), this might reflect an overall nutritional status that is independent of the energy source (lipids, proteins or sugars). Reducing sugars are rare in haemolymph and are therefore a good indicator of honeydew uptake, regardless of their low proportion in honeydew [nevertheless sometimes exceeding $50 \%$ of all sugars, see for instance Fischer \& Schingleton (2001) or Blüthgen et al. (2004)]. Total and reducing sugar concentrations can be readily measured using chemical (photometric) methods, allowing the evaluation of nutritional status and indication of honeydew utilization by L. microcephalum in a perhaps old-fashioned but efficient way.

\section{MATERIAL AND METHODS}

\section{Ant collection}

This study was conducted in Southern Moravia (south-eastern Czech Republic), which is on the north-western margin of this species' range but where there is a very large population of $L$. microcephalum (Schlaghamerský \& Omelková, 2007). Ants were collected in an old forest stand (Rendezvous National Nature Monument) between the towns of Valtice and Břeclav in Southern Moravia, Czech Republic (48 $\left.44^{\prime} 52^{\prime \prime} \mathrm{N}, 16^{\circ} 47^{\prime} 33^{\prime \prime} \mathrm{E}\right)$, where 42 colonies (nest trees) were recorded in a preceding study, which is the third largest subpopulation in the South Moravian population (Omelková, unpubl. data; see also Schlaghamerský \& Omelková, 2007). In 2009, workers of $L$. 
microcephalum ascending and descending nest and foraging trees were collected once per month on April 23, May 20, June 24 and July 22. This includes the species' main activity period as in August the activity of workers declined rapidly and foraging trees were hardly visited anymore. On each of the above dates, the ants were collected from ca 9:00 to 11:30 and 13:00 to 16:30 (collecting was time consuming and we wanted to avoid the period of low activity around noon). Workers ascending and descending were collected at a height of $1.5 \mathrm{~m}$ above the ground from trunks of nest and foraging trees (both oak). Whereas nest trees, which were previously marked, can be also distinguished from foraging trees by their greater size and higher abundance of Liometopum workers, it was in many cases not possible to establish links between individual nests and foraging trees mainly due to the dense undergrowth. In particular, workers ascending nest trees could have visited one of several foraging trees monopolized by a particular colony. Several of the colonies and their foraging trees were adjacent to each other but it was not always clear which foraging trees were visited by which colony. Therefore, we did not use a paired sampling design, although we collected ants from foraging trees close to the nest trees selected. Even in the course of a single year L. microcephalum colonies were observed to change foraging trees or the intensity with which individual trees were visited. For this reason, we randomly selected nest trees and nearby foraging trees currently well-visited by L. microcephalum from which to collect ants on each sampling date. Distances between nest trees at the study site ranged between 12 and $25 \mathrm{~m}$, and that between nest and foraging trees of the same colony between 2 and $10 \mathrm{~m}$.

From each tree 5 ascending and 5 descending workers were collected from the bark of the trunk with entomological forceps. The workers were placed in plastic tubes (pooled separately for each combination of type of tree and direction of movement), which were immediately placed in an ice box with carbondioxide ice $\left(-80^{\circ} \mathrm{C}\right)$ in order to prevent the ants from excreting or regurgitating their crop contents when stressed. Back in the laboratory, the tubes with the ants were stored in a freezer at $-20^{\circ} \mathrm{C}$ for up to four months. Ten nest trees and the same number of foraging trees, randomly chosen anew on each sampling date, were sampled on each occasion. Thus 50 ascending and 50 descending workers were collected on each date sampled from each type of tree (nest vs foraging tree), which resulted in 200 specimens being collected on each date sampled and a total of 800 for both types of trees on the four dates sampled. From these, 20 workers for each combination of type of tree $\times$ direction of movement $x$ date sampled were randomly selected for analysis ( 80 specimens per date, 320 in total).

\section{Analysis of gaster mass and sugar content}

The ants were taken out of the freezer and as soon as they became supple, 20 specimens from a given tube were taken (see above) and the gaster of each ant cut off and placed on filter paper to absorb the water that condensed on its surface and subsequently weighed on an analytical balance (Sartorius R 160P, precision to $0.02 \mathrm{mg}$ ). Gaster mass was recorded as fresh weight (fw). We did not observe any loss of liquid when the gasters were cut off, as they were still partially frozen.

As the composition of the honeydew collected by the ants and its potential variability in time were unknown, we analyzed both the concentrations of total and reducing sugars in the ant gasters. Although reducing sugars were assumed to be a better indicator of trophobiosis, see above, we were not sure if their content would be sufficient to obtain meaningful results. Each cut off and weighed gaster was homogenized in $1 \mathrm{ml}$ of chloroform-methanol $(1: 2)$. The solution of the sugars in chloroform-methanol was the first step in separating them from the glycogen also present in the homogenized sample (Olson et al., 2000). The second step was centrifuging $(12,000 \mathrm{~g} / 3 \mathrm{~min})$ the sample, which separated the sedimented glycogen from the soluble sugars in the supernatant. The supernatant was divided between two microcentrifuge tubes for subsequent analyses of reducing sugars $(600 \mu \mathrm{l})$ and total sugars $(100 \mu \mathrm{l})$. These analyses were done separately for individual gasters of the ants.

Total sugars were assessed using the hot-anthrone test (Olson et al., 2000). The tube with $100 \mu 1$ of supernatant was placed in a hot water bath $\left(90^{\circ} \mathrm{C}\right)$ and the solution evaporated to $50 \mu \mathrm{l}$. After evaporation the sample was cooled in cold water and 950 $\mu 1$ of anthrone reagent (120 mg of anthrone in $100 \mathrm{ml} 20 \%$ $\mathrm{H}_{2} \mathrm{SO}_{4}$ ) was added. The solution was well mixed and again placed in the hot water bath $\left(90^{\circ} \mathrm{C}\right)$ for $15 \mathrm{~min}$. After cooling, the absorbance at $625 \mathrm{~nm}$ was recorded (Synergy 2 microplate reader, BioTek Instruments, Inc.).

Reducing sugars were assessed using the Somogyi-Nelson method (Nelson, 1944). A microcentrifuge tube containing 600 $\mu \mathrm{l}$ of sample was placed in a hot water bath $\left(90^{\circ} \mathrm{C}\right)$ and the solution evaporated to $50 \mu \mathrm{l}$. $150 \mu \mathrm{l}$ of distilled water was added to the tube. To remove proteins we added $100 \mu 10.3 \mathrm{~N} \mathrm{Ba}(\mathrm{OH})_{2}$ and $100 \mu 15 \% \mathrm{ZnSO}_{4}$. Deproteination took $10 \mathrm{~min}$, after which the sample was centrifuged $(6,000 \mathrm{~g} / 7 \mathrm{~min}) .200 \mu \mathrm{l}$ of the sample and $200 \mu 1$ of Somogyi-Nelson reagent were poured into a new micro-centrifuge tube and this was placed in the hot water bath $\left(90^{\circ} \mathrm{C}\right)$ for $15 \mathrm{~min}$. After cooling, $200 \mu \mathrm{l}$ of arsenmolybden reagent was added, the solution was mixed and the absorbance at $670 \mathrm{~nm}$ recorded.

Photometric measurements yielded the concentrations of the different sugars. By multiplying by gaster mass the absolute sugar content of each gaster was obtained.

\section{Data analysis}

To model the relationships between the mean amount of sugar and type of tree, direction of movement and month, we used Generalized Linear Models (GLM) in R 2.10.1 software (R Development Core Team, 2011). As the data did not fulfil the requirements for homogeneity of variances and normality of distribution, we corrected for gamma and log-normal distribution (family $=$ Gamma) using inverse or identity link. We modelled three response variables: gaster mass, reducing sugar content and total sugar content. We used one model with sugar contents represented by concentrations for individual ant gasters $(\mu \mathrm{g} / \mathrm{mg}$ fresh weight of gaster) and one model with the absolute values ( $\mu \mathrm{g} /$ gaster). We used, "type of tree $\times$ direction" (nest tree up, nest tree down, foraging tree up, foraging tree down) and "month" (IV-VII) as categorical explanatory variables. In the case of sugar concentrations we used "gaster mass" as another explanatory variable (possible relationship between sugar concentration and worker size). We also checked models using "direction" (up, down) and "type of tree" as separate variables, but - in agreement with our hypotheses - "direction" as such had no effect in any model (e.g., ants leaving the nest tree to forage and returning from foraging trees had the same "direction" but on different types of trees). We always started the modelling with the most complex models, that is, we tried to determine the effects of all the explanatory variables and their interactions and fitted models by backward selection. We used F-tests to test the significance of individual explanatory variables and Akaike Information Criteria (AIC) to test the suitability of the model by comparing the AICs of several models, the smaller the AIC the better the model, and diagnostic plots with analyses of residuals and Cook's distances to select the best model. The differences between values ("levels" in R) of response variables were assessed within the GLMs by t-tests, using a treatment contrast matrix. In the models for total and 
reducing sugars, one and four outliers (exceeding the other values two to three times), respectively, were excluded because we were not sure if these values were not the result of measurement errors.

\section{RESULTS}

We selected the most suitable model for each dependent variable based on the significance of the explanatory variables; for detailed characteristics see Table 1.

In case of gaster mass only the explanatory variable "type of tree $\times$ direction" had a significant effect (Table 1). Pooled over all sampling dates, workers descending foraging trees had significantly greater gaster masses than those descending nest trees or ascending foraging trees ( $p$ $<0.05)$. Gasters of workers ascending nest trees had the greatest masses and differed significantly $(p<0.05)$ from those of the other three groups of workers (Fig. 2). Values for the different dates (months), showed a similar trend (Fig. 3). Between-month differences in gaster mass were not significant.

In the case of the total sugar concentrations in ant gasters, all explanatory variables had an important effect (Table 1). The mean value for the whole sampling season was significantly higher for workers descending foraging trees than those descending nest trees and also those ascending nest trees ( $p<0.05$ in both cases). The lowest concentration of total sugars was recorded in July (Fig. 4, Fig. 5) and differed significantly $(\mathrm{p}<0.05)$ from the high concentration found in April and June. The concentration of total sugars was positively related to worker gaster mass (regression coefficient 3.72, $p=0.02$ ).

Also in the case of the concentrations of reducing sugars, all explanatory variables had significant or, in the case of "month", marginally significant effects (Table 1). The mean value was again significantly higher $(p<0.05)$ for workers descending foraging trees than those either descending or ascending nest trees (Fig. 6). The same trend was apparent for each of the dates (Fig. 7). The concentration of reducing sugars was also correlated with gaster mass (regression coefficient 5.18, $\mathrm{p}=0.0367$ ).

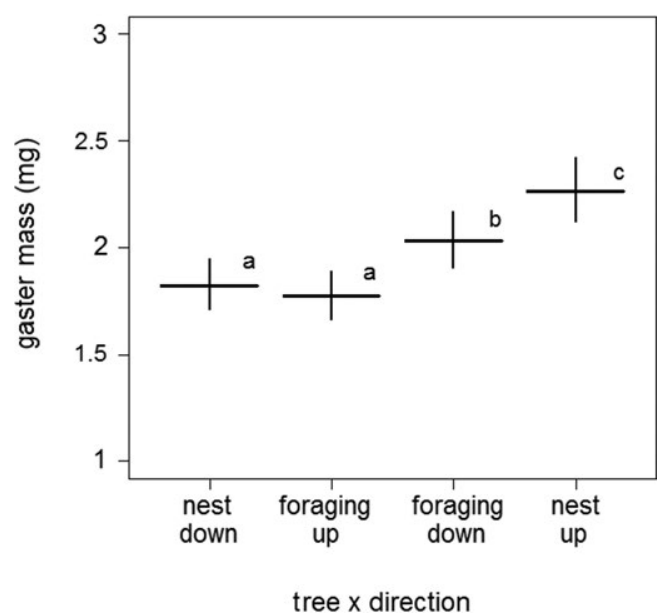

Fig. 2. Differences in gaster mass of L. microcephalum workers associated with the direction of movement (up and down) on nest and foraging trees (all dates sampled); predicted values [model formula: GLM (Total sugar concentration $\sim$ type of tree $\times$ direction, family $=$ Gamma)]: mean values with $95 \%$ confidence intervals; values with different letters are significantly different (t-test, $\mathrm{p}<0.05$ at least, details see text and Table 1); $\mathrm{n}=320$.

By-far the lowest concentration of reducing sugars was recorded in April and the highest in June (difference between these months was significant at $\mathrm{p}<0.05$; Fig. 6).

The absolute contents of total sugars and reducing sugars in ant gasters were only associated with the explanatory variable "type of tree $\times$ direction". There were no significant seasonal differences (Table 1). In the case of total sugars, their mean content was significantly greater in workers descending than those ascending foraging trees $(\mathrm{p}<0.05$; Fig. 8) and also greater than in those descending from nest trees $(p<0.0001)$. The mean content of total sugars was also greater in workers ascending than descending from nest trees $(p<0.05)$. The mean content of reducing sugars was greater in workers descending foraging trees than in those descending from nest trees $(\mathrm{p}<0.0001)$, ascending foraging trees $(\mathrm{p}<$

TABLE 1. Outputs of the best models obtained by the method of GLM, giving model formula (in R), Akaike information criterion (AIC), degrees of freedom (Df), explained variablity as decimal fraction of one $\left(\mathrm{R}^{2}\right)$, explanatory variables, F statistics and respective p-values.

\begin{tabular}{|c|c|c|c|c|c|c|}
\hline Model formula & AIC & Df & $\mathrm{R}^{2}$ & Predictor variable & F-test & p-value \\
\hline $\begin{array}{l}\text { GLM }[\text { Gaster mass } \sim \text { typeoftree } \times \text { direction, } \\
\text { family }=\text { Gamma }(\text { link }=\text { identity })]\end{array}$ & 534.42 & 5 & 0.1016 & typeoftree $\times$ direction & 11.39 & $<0.0001$ \\
\hline \multirow{3}{*}{$\begin{array}{l}\text { GLM (Total sugar concentration } \sim \text { typeoftree } \times \text { direction } \\
\quad+\text { month }+ \text { gaster mass, family }=\text { Gamma })\end{array}$} & \multirow{3}{*}{2752.6} & \multirow{3}{*}{9} & \multirow{3}{*}{0.0906} & typeoftree $\times$ direction & 5.31 & 0.0014 \\
\hline & & & & month & 3.8 & 0.0106 \\
\hline & & & & gaster mass & 5.47 & 0.02 \\
\hline $\begin{array}{c}\text { GLM (Total sugar amount } \sim \\
\text { typeoftree } \times \text { direction, family }=\text { Gamma) }\end{array}$ & 3287.5 & 5 & 0.0573 & typeoftree $\times$ direction & 5.97 & 0.0006 \\
\hline \multirow{3}{*}{$\begin{array}{c}\text { GLM (Reducing sugar concentration } \sim \text { typeoftree } \times \text { direction } \\
+ \text { gaster mass }+ \text { month, family }=\text { Gamma })\end{array}$} & \multirow{3}{*}{2443.7} & \multirow{3}{*}{9} & \multirow{3}{*}{0.0862} & typeoftree $\times$ direction & 7.17 & 0.0001 \\
\hline & & & & gaster mass & 4.41 & 0.0367 \\
\hline & & & & month & 2.53 & 0.0571 \\
\hline $\begin{array}{l}\text { GLM (Reducing sugar amount } \sim \\
\text { typeoftree } \times \text { direction, family }=\text { Gamma) }\end{array}$ & 2889.1 & 3 & 0.0576 & typeoftree $\times$ direction & 7.69 & $<0.0001$ \\
\hline
\end{tabular}




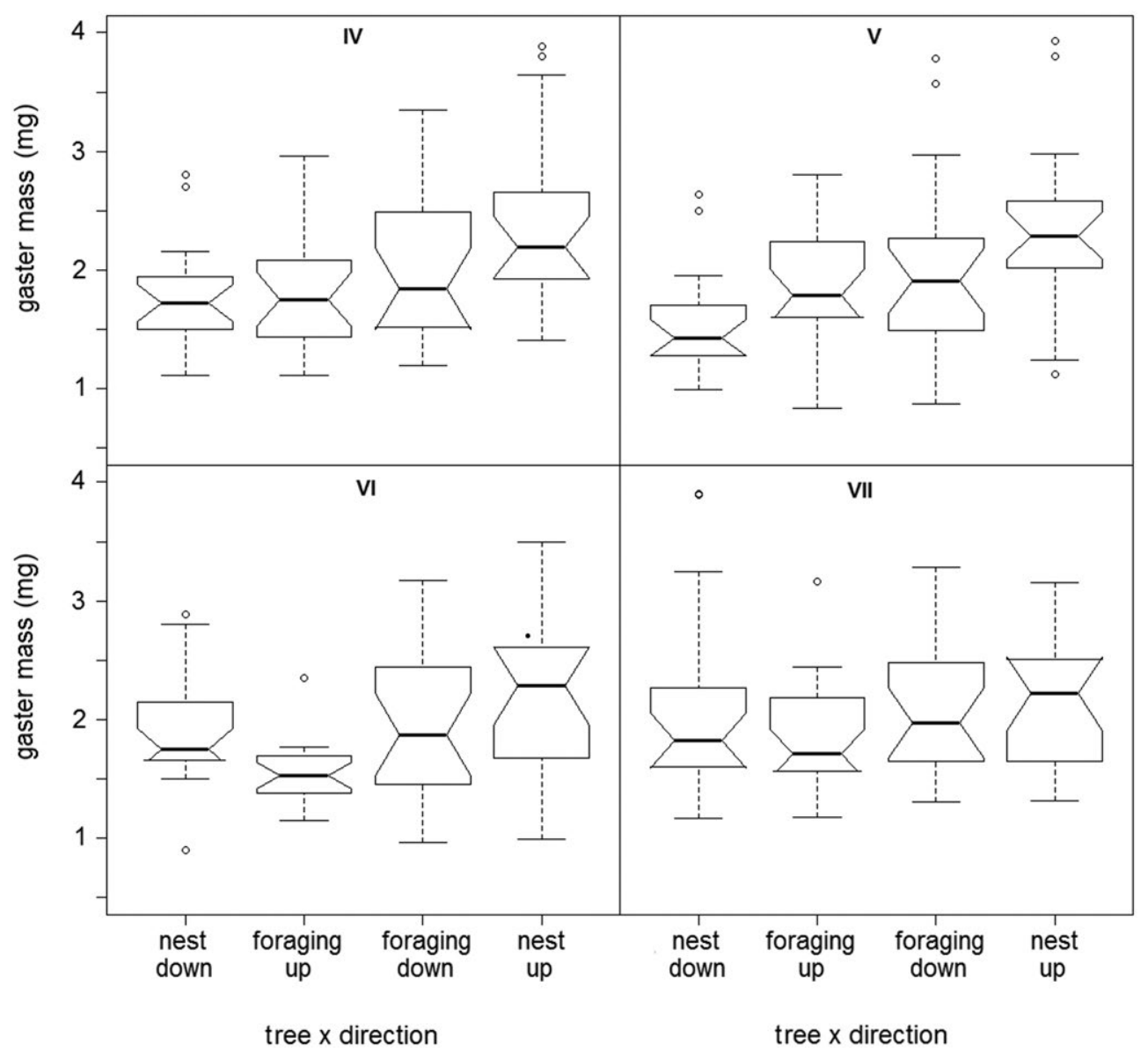

Fig. 3. Gaster mass of L. microcephalum workers associated with the direction of movement on nest and foraging trees on four dates in the period April-July (IV-VII); measured values: medians (bars) with 95\% confidence limits (notches), 25-75\% quantils (boxes), 1.5 interquartile ranges (whiskers) and outliers (circles); $\mathrm{n}=320$.

$0.05)$ and even than those ascending nest trees $(\mathrm{p}<0.05$; Fig. 9).

\section{DISCUSSION}

The observed differences in gaster mass support our hypothesis that liquid food is transported from foraging to nest trees. Differences between the gaster mass of workers were most pronounced in April and May between workers ascending and descending nest trees (Fig. 3). The difference in sugar content on foraging trees, where ascending workers contained less than descending workers, seems logical, because a worker ascending a foraging tree should have an empty crop and be hungry, thus contain less total sugars and in particular less reducing sugars than a worker leaving a foraging tree, presumably satiated after foraging. The observed pattern is in accordance with our expectation that differences between the ants' directions of movement would be more reflected in reducing than in total sugars. The comparison of sugar concentrations in workers descending and ascending the nest tree did not confirm higher concentrations in gasters of in-coming than in those leaving nest trees. In contrast, the concentration of reducing sugars in ants ascending seemed to be somewhat lower (not statistically significant) than those descending from nest trees. The same was true for the absolute content of reducing sugars.

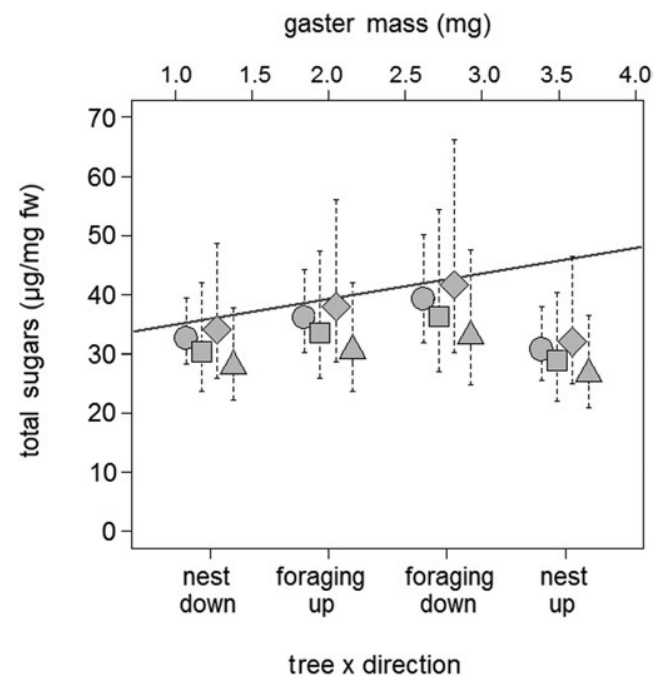

Fig. 4. Differences in total sugar concentration in the gasters of L. microcephalum workers associated with the direction of movement (up and down) on nest and foraging trees (lower $\mathrm{x}$-axis), sampling dates and gaster mass; predicted values (model formula: GLM (Total sugar concentration $\sim$ type of tree $x$ direction + month + gaster mass, family $=$ Gamma $)$, details see Table 1): mean values with $95 \%$ confidence intervals; $\bigcirc-$ April, $\square-$ May, $\diamond-$ June, $\Delta-$ July; regression line shows the relation between total sugar content and gaster mass (regression coefficient $=3.72$ ), scale for gaster mass on upper $\mathrm{x}$-axis applies. 


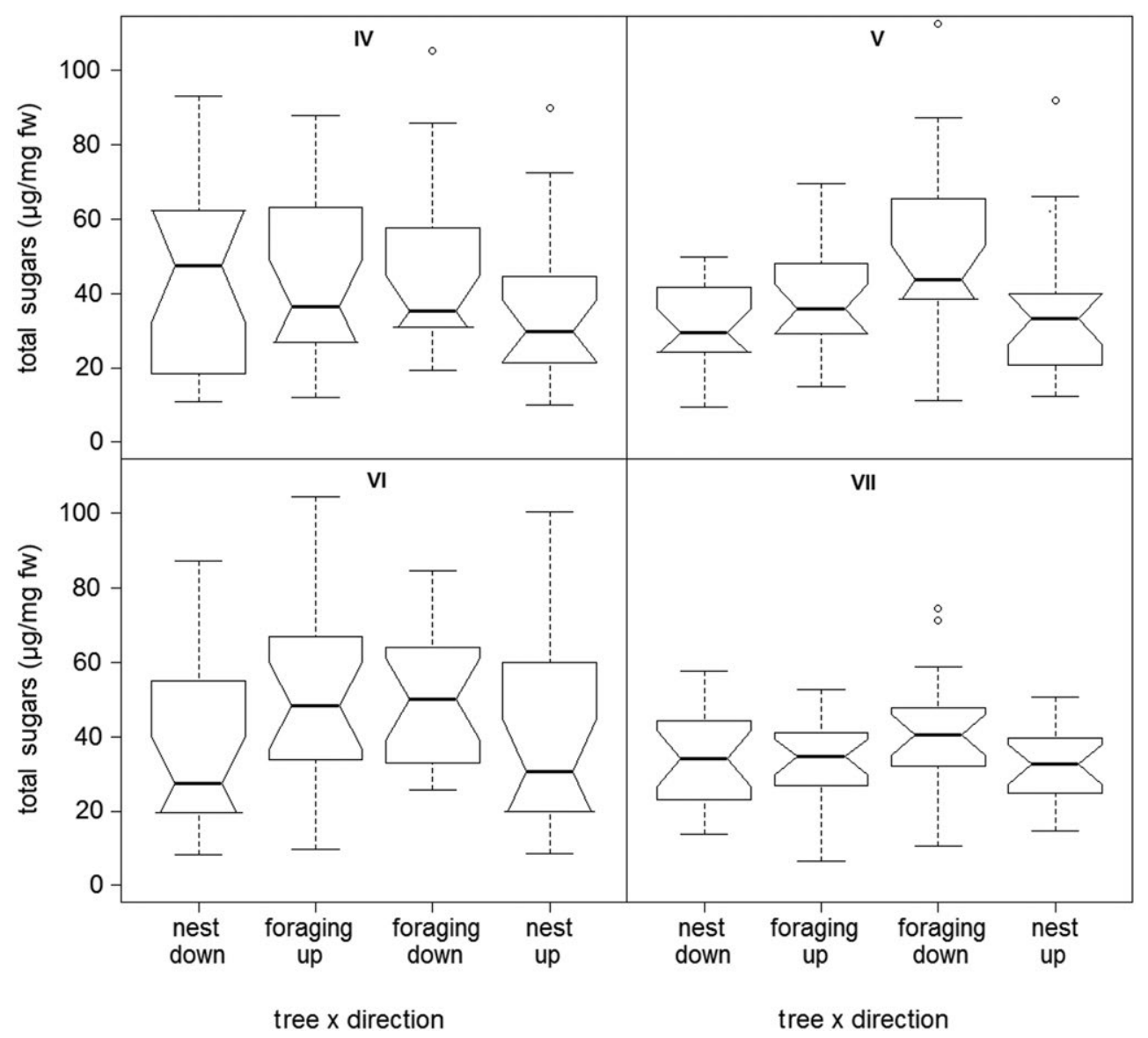

Fig. 5. Total sugar concentration in the gasters of L. microcephalum workers associated with the direction of movement on nest and foraging trees on four dates in the period April-July (iv-vii); measured values: medians (bars) with $95 \%$ confidence limits (notches), 25-75\% quantils (boxes), 1.5 interquartile ranges (whiskers) and outliers (circles); $\mathrm{n}=320$.

However, the absolute content of total sugars per gaster was significantly higher in workers ascending than descending from nest trees. The less convincing results obtained for nest trees might have had several reasons. Some of the returning foragers might not have collected any honeydew. There are many more workers moving around on the trunks of nest than of foraging trees, presumably doing different tasks, including guarding the territory (Petráková \& Schlaghamerský, 2011), and the correct sampling of workers returning from foraging and those leaving to forage is more difficult than on foraging trees. Several outlying values of a high sugar content and the connected non-homogeneous variance support this notion. Some transfer of liquid food (trophallaxis) from in-coming workers to those on the lower part of the trunk of nest trees might take place. Furthermore, although the files of workers ascending to the crowns of trees indicate that a substantial portion of the foraging occurs there, we have observed L. microcephalum tending Stomaphis quercus in bark fissures even on the lowest parts of oak trunks, including those of nest trees. On the other hand, some of the ants collected descending nest trees might have tended aphids further up the nest tree and by-passed the nest. Due to the hidden position of a colony's nest (often in the trunk several metres above ground) the flow of food towards the nest is difficult to study on the nest

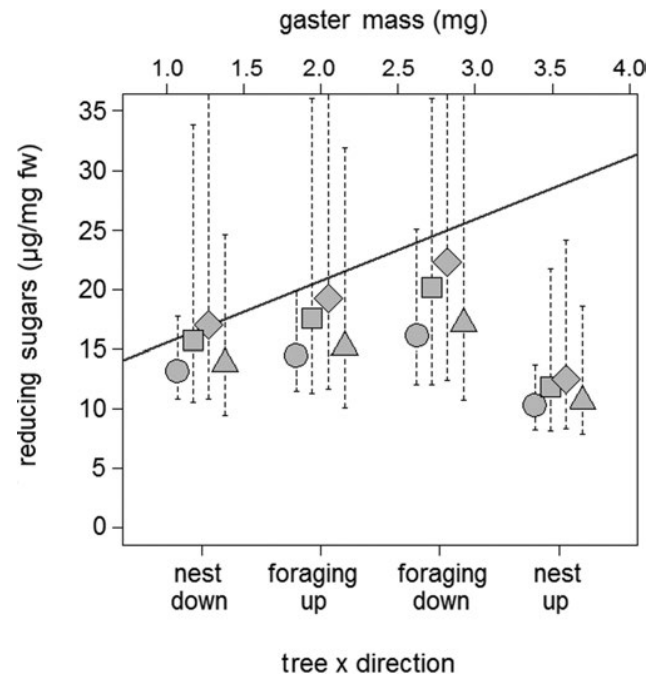

Fig. 6. Differences in the concentration of reducing sugars in the gasters of $L$. microcephalum workers associated with the direction of movement (up and down) on nest and foraging trees (lower $\mathrm{x}$-axis), dates sampled and gaster mass; predicted values (model formula: GLM (Reducing sugar concentration $\sim$ type of tree $\times$ direction + gaster mass + month, family $=$ Gamma), details see Table 1): mean values with $95 \%$ confidence intervals; $\odot-$ April, $\square$ - May, $\diamond-$ June, $\Delta-$ July; regression line shows the relation between total sugar content and gaster mass (regression coefficient $=5.18$ ), scale for gaster mass on upper $\mathrm{X}$-axis applies. 


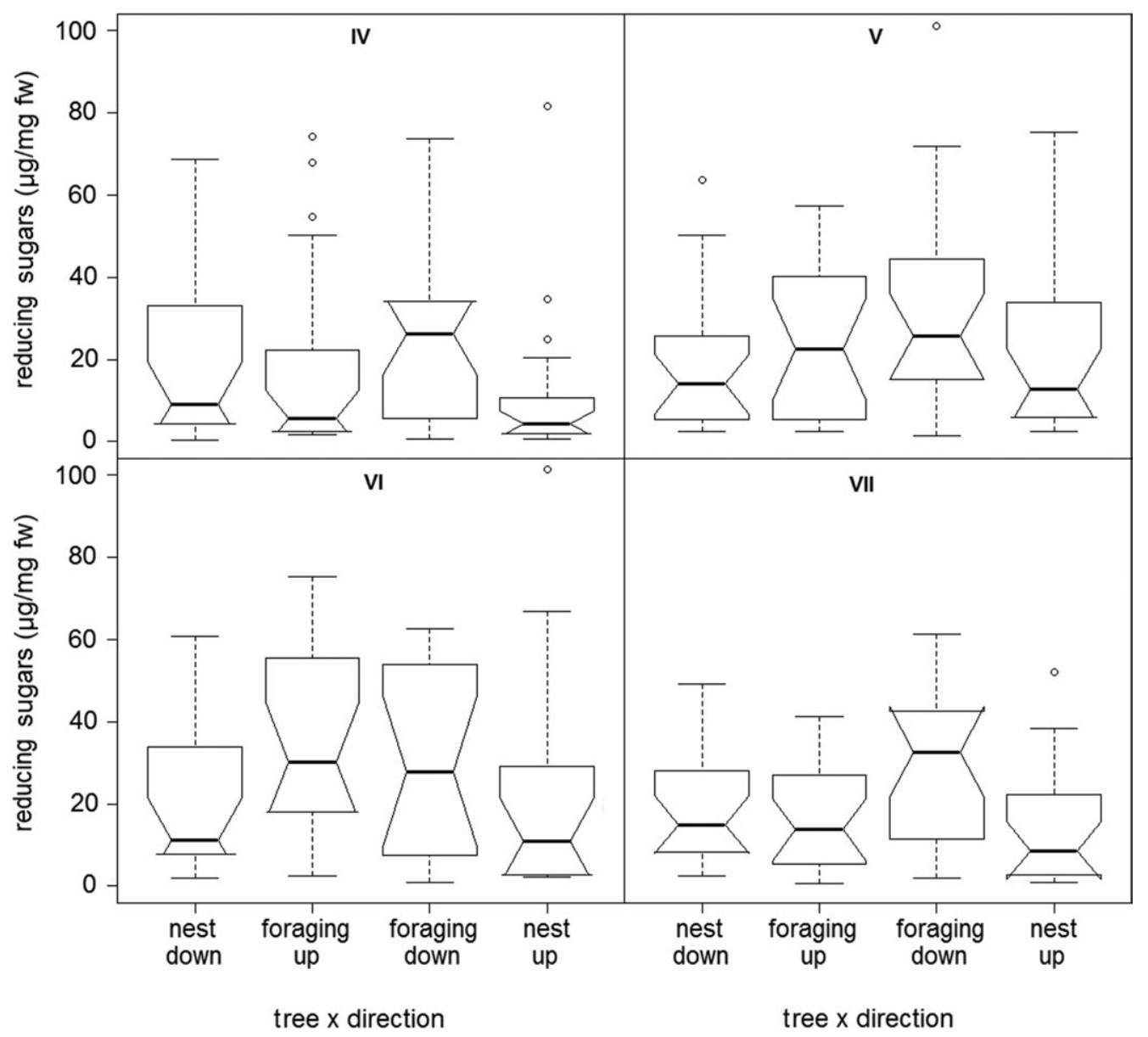

Fig. 7. Content of reducing sugars in the gasters of L. microcephalum workers associated with the direction of movement on nest and foraging trees on four dates in the period April-July (IV-VII); measured values: medians (bars) with $95 \%$ confidence limits (notches), 25-75\% quantils (boxes), 1.5 interquartile ranges (whiskers) and outliers (circles); $\mathrm{n}=320$.

tree. One of the reasons for L. microcephalum preferring to nest in live trees (Schlaghamerský \& Omelková, 2007) might be the importance of a sufficient source of honeydew in the close vicinity of the nest because foraging on distant trees carries substantial additional costs, particularly for those colonies in solitary trees growing in meadows and similar habitats.

The concentration of reducing sugars in ant gasters was lower in April than in May and June. The concentration of total sugars was somewhat lower in May for unknown reasons, but as explained above reducing sugars should be a better indicator of recent honeydew uptake. Thus our hypothesis that honeydew would be most important in spring was not confirmed. We assume this was due to the low population densities of aphids at the beginning of the observation period. We have no data on aphid dynamics in this area but substantial increases in the abundance of tree-dwelling aphids from April to May are recorded for temperate regions, for instance, by Sequeira \& Dixon (1997), Jarošík \& Dixon (1999), Molnár (2003) and Durak (2008). However, we have no explanation for the high gaster mass and low concentration of sugars in workers returning to nest trees in April compared to the other groups of workers (Figs 3, 5, 7). Transport of water in the crop would seem more probable during the summer

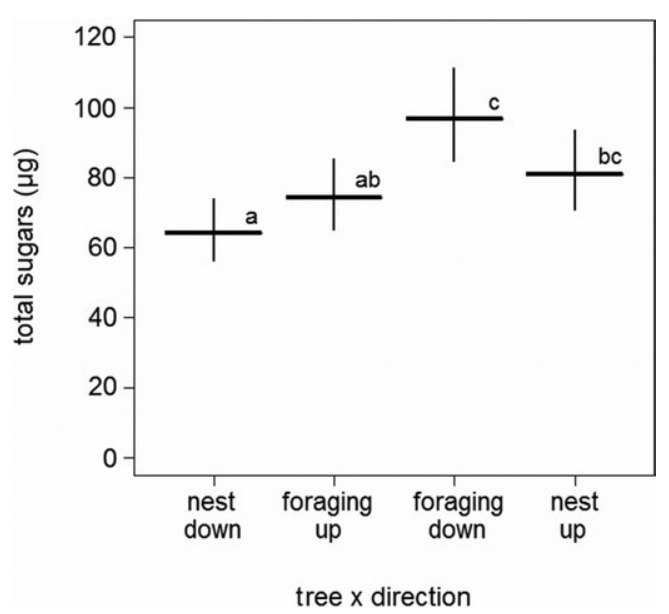

Fig. 8. Differences in the absolute content of total sugars in gasters of L. microcephalum workers associated with the direction of movement (up and down) on nest and foraging trees (all sampling dates); predicted values [model formula: GLM (Total sugar $\sim$ type of tree $\times$ direction, family $=$ Gamma)]: mean values with $95 \%$ confidence intervals; values not sharing the same letters are significantly different (t-test, $p<0.05$ at least, details see text and Table 1 ); $\mathrm{n}=320$. 


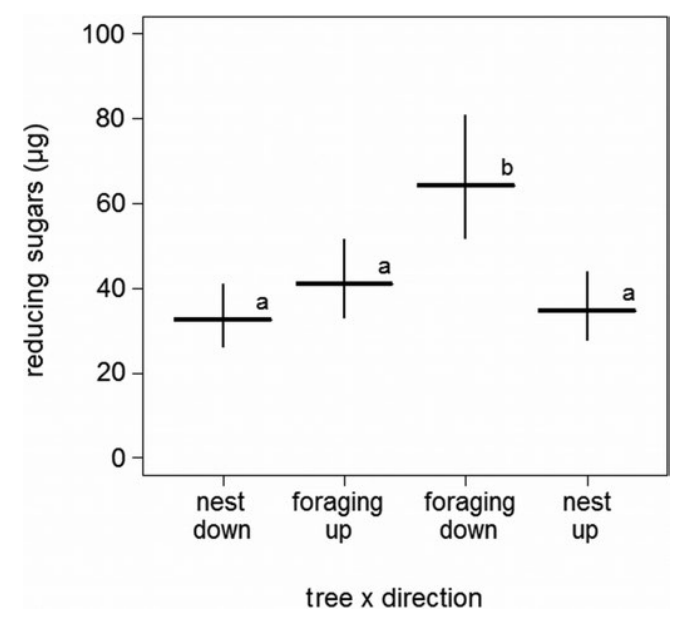

Fig. 9. Differences in the absolute content of reducing sugars in gasters of L. microcephalum workers associated with the direction of movement (up and down) on nest and foraging trees (all sampling dates); predicted values [model formula: GLM (Total sugar $\sim$ type of tree $\times$ direction, family $=$ Gamma)]: mean values with $95 \%$ confidence intervals; values with different letters are significantly different (t-test, $\mathrm{p}<0.05$ at least, details see text and Table 1$) ; \mathrm{n}=320$.

months. Moreover, as shown, at least for Formica polyctena, water probably passes quickly to the mid-gut and is not stored in the crop (Schneider, 1966). Liquid food other than honeydew could have confounded the results. Possibly some nectar of low sugar content was collected elsewhere in the vicinity in April, but we have no observations that support this assumption. Many aphid populations decrease substantially in mid to late summer (references see above), which might explain the slight decrease in total and reducing sugars (value for reducing sugars not significantly different from that recorded on any of the other dates) found in the ants in July (Figs 4, 6) and, in particular, the observed very low presence of $L$. microcephalum on foraging trees in August (not necessarily due to trophobiosis as ants are also predators of aphids - see for instance Novgorodova, 2005). Species of trees frequently visited by foraging $L$. microcephalum are oaks and poplars, both of which lack nectaries, so honeydew is the only source of such food on these trees. We conclude that trophobiosis is an important part of foraging in L. microcephalum and a major reason why workers visit foraging trees. Trees in which the colonies build their nests also seem to be important for the colonies' nutrition, including trophobiosis. We are not yet able to give a quantitative assessment of the importance of honeydew for L. microcephalum in relation to other types of food. A study of further aspects of foraging by the South Moravian population of L. microcephalum is underway. In the light of the present data, however, we assume that predation is not such a dominant part of the foraging behaviour of $L$. microcephalum as has formerly been reported. This is also interesting in light of comparisons between canopy and litter dwelling ants based on tropical assemblages (e.g. Hahn \& Wheeler, 2002), as $L$. microcephalum is one of the few truly arboricolous ants in the temperate zone but has behavioural traits similar to those of many arboricolous ant species in the tropics (agressiveness, territoriality, numerical dominance). These comparisons have shown that canopy dwelling ants are nitrogen-limited and epigeic species carbohydratelimited and have different food preferences (protein-rich prey in the former vs. honeydew in the latter). However, this does not mean that the former group does not utilize trophobiosis and the latter predation, but that the scarcer food source is preferred when available. This is in line with the many reports about the predacious behaviour of L. microcephalum (see above) and does not contradict our present findings.

ACKNOWLEDGEMENTS. The study was supported by the Ministry of Education, Youth and Sports of the Czech Republic, Research Plan No. MSM0021622416. L. Petráková received additional funding from the Czech Science Foundation (grant 526/09/H050). The Czech Ministry of the Environment granted access to the Rendezvous National Nature Monument and allowed us to collect specimens of L. microcephalum by granting us Exception No. 8375/04-620/1377/04. The Master's thesis of M. Omelková (Masaryk University, Brno), provided initial information on the feeding biology of L. microcephalum and a starting point for the present study. Two anonymous reviewers and J. Dauber (Thünen Institute, Braunschweig) provided valuable comments that were incorporated in the final version of the manuscript. Further advice on the statistical analysis of the results was given by P. Drozd (Ostrava University). M. Barclay (Natural History Museum, London) and A.F.G. Dixon kindly checked the English.

\section{REFERENCES}

Blüthgen N., Verhaag M., Goitía W., Jaffé K., Morawetz K. \& BARTHLOTT W. 2000: How plants shape the ant community in the Amazonian rainforest canopy: the key role of extrafloral nectaries and homopteran honeydew. - Oecologia 125: $229-240$.

Blüthgen N., Gottsberger G. \& Fiedler K. 2004: Sugar and amino acid composition of ant-attended nectar and honeydew sources from an Australian rainforest. - Austral. Ecol. 29: 418-429.

Boevé J.-L. \& WÄckers F.L. 2003: Gustatory perception and metabolic utilization of sugars by Myrmica rubra ant workers. - Oecologia 136: 508-514.

Durak R. \& WoJcIechowsKi W. 2008: Structure and dynamics of aphid communities connected with trees in selected forest associations. - Pol. J. Entomol. 77: 79-92.

EMERY C. 1891: Zur Biologie der Ameisen. - Biol. Zentralbl. 11: $165-180$.

Fiedler K., Kuhlmann F., Schlick-Steiner B.C., Steiner F.M. \& Gebauer G. 2007: Stable N-isotope signatures in central European ants - assessing positions in a trophic gradient. Insectes Soc. 54: 393-402.

Fischer M.K. \& Schingelton A.W. 2001: Host plant and ants influence the honeydew sugar composition of aphids. Funct. Ecol. 15: 544-550.

Fischer M.K., VÖLKL W. \& HoffMAnN K.H. 2005: Honeydew production and honeydew sugar composition of polyphagous black bean aphid, Aphis fabae (Hemiptera: Aphididae) on various host plants and implications for ant-attendance. Eur. J. Entomol. 102: 155-160.

Forel A. 1892: Die Ameisenfauna Bulgariens. - Verh. K.-K. Zool.-Bot. Ges. Wien 42: 305-318. 
GoIDANICH A. 1959: Le migrazioni coatte mirmecogene dello Stomaphis quercus Linnaeus, afide olociclico monoico omotopo. - Boll. Ist. Entomol. Univ. Studi Bologna 23: 93-131.

Hahn D.A. \& Wheeler D.E. 2002: Seasonal foraging activity and bait preferences of ants on Barro Colorado Island, Panama. - Biotropica 34: 348-356.

Hölldobler B. \& Wilson E.O. 1990: The Ants. Belknap Press of Harvard University Press, Cambridge, MA, 732 pp.

HopkINS G.W. \& THACKER J.I. 1999: Ants and habitat specificity in aphids. - J. Insect Conserv. 3: 25-31.

JARošík V. \& Dixon A.F.G. 1999: Population dynamics of a tree-dwelling aphid: regulation and density-independent processes. - J. Anim. Ecol. 68: 726-732.

MAKAREVICH O.N. 2003: Liometopum microcephalum (Hymenoptera, Formicidae) in the Lower Dnepr. - Vest. Zool. 37(4): 51-56 [in Ukrainian, Engl. abstr.].

MAYR G. 1856: Beiträge zur ungarischen Formicidenfauna. Verh. Zool.-Bot. Ges. Wien 6: 175-178.

MolnáR N. 2003: Population dynamics features of willowfeeding aphids. - Acta Phytopathol. Entomol. Hung. 38: 125-135.

Nelson N. 1944: A photometric adaptation of the Somogyi method for the determination of glucose. $-J$. Biol. Chem. 153: $375-380$

Novgorodova T.A. 2005: Ant-aphid interactions in multispecies ant communities: Some ecological and ethological aspects. Eur. J. Entomol. 102: 495-501.

Olson D.M., Fadamiro H., Lundgren J.G. \& Heimpel G.E. 2000: Effects of sugar feeding on carbohydrate and lipid metabolism in a parasitoid wasp. - Physiol. Entomol. 25: $17-26$.

Petráková L. \& Schlaghamerský J. 2011: Interactions between Liometopum microcephalum (Formicidae) and other dominant ant species of sympatric occurrence. - Commun. Ecol. 12: 9-17.

R Development Core Team 2011: A Language and Environment for Statistical Computing. R Foundation for Statistical Computing, Vienna. URL: http://www.R-project.org

Schilman P.E. \& Roces F. 2008: Haemolymph sugar levels in a nectar-feeding ant: dependence on metabolic expenditure and carbohydrate deprivation. - J. Comp. Physiol. (B) 178: $157-165$.

Schlaghamerský J. \& Omelková M. 2007: The present distribution and nest tree characteristics of Liometopum microcephalum (Panzer, 1798) (Hymenoptera: Formicidae) in South Moravia. - Myrmecol. News 10: 85-90.

SCHNEIDER P. 1966: Versuche zur Frage der Futterverteilung und Wasseraufnahme bei Formica polyctena (Först.). - Insectes Soc. 13: 297-304.

SeIFert B. 2007: Die Ameisen Mittel- und Nordeuropas. Lutra Verlags und Vertriebsgesellschaft, Görlitz / Tauer, 368 pp.

Sequeira R. \& Dixon A.F.G. 1997: Population dynamics of treedwelling aphids: The importance of seasonality and time scale. - Ecology 78: 2603-2610.

Stadler B. \& Dixon A.F.G. 2008: Mutualism: Ants and their Insect Partners. Cambridge University Press, New York, 219 pp.

Velasco Corona C., Corona-Vargas M.C. \& Peńa-Martínez R. 2007: Liometopum apiculatum (Formicidae: Dolichoderinae) y su relacion trofobiotica con Hemiptera Sternorrhyncha en Tlaxco, Tlaxcala, México. - Acta Zool. Mexicana (n.s.) 23(2): 31-42.

WheELER W.M. 1905: The North American ants of the genus Liometopum. - Bull. Am. Mus. Nat. Hist. 21: 321-333.

WIEST L. 1967: Zur Biologie der Ameise Liometopum microcephalum Panz. - Wiss. Arb. Bgld 38: 136-144.

Received February 28, 2011; revised and accepted October 23, 2012 